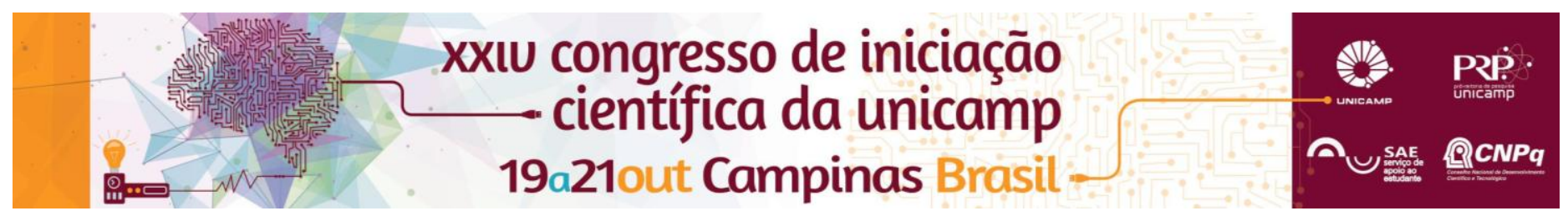

\title{
A incidência do diastema interincisivos centrais superiores na dentição mista
}

\author{
Rúbia V F Santos*, Maria Beatriz B A Magnani, Vania C V Siqueira
}

\section{Resumo}

O projeto investigou a incidência do diastema interincisivos centrais superiores em pacientes com dentição mista que realizavam tratamento odontológico na clínica de Odontologia Infantil da FOP UNICAMP. O diagnóstico dessa anormalidade oclusal empregou minuciosamente exames clínicos e radiográficos que permitiram verificar que os fatores etiológicos associados aos diastemas incluem a presença de dentes conóides e/ou mesiodens, a inserção anormal do freio labial superior, o septo ósseo interincisivos amplo, a fusão imperfeita da linha média e hábitos bucais deletérios. O projeto indicou a incidência dos diastemas na clínica de Odontologia Infantil da FOP, correlacionou os possíveis fatores etiológicos com os diversos graus de diastemas observados e sugeriu os possíveis e mais indicados tratamentos ortodônticos para cada caso.

Palavras-chave: distemas, incisivos centrais superiores, dentição mista

\section{Introdução}

Diastemas são espaços que ocorrem entre dois ou mais dentes e quando ocorre entre os incisivos centrais superiores são denominados de diastemas medianos ou da linha média. Comuns na dentadura decídua e na fase do "patinho feio" na dentição mista que normalmente se fecham com o crescimento e maturação da dentição. Mas a presença de dentes conoides e/ou mesiodens, agenesias de incisivos laterais superiores, inserção baixa do freio labial superior, septo ósseo volumoso, fusão imperfeita da linha média, discrepâncias no tamanho dos dentes superiores com o osso alveolar e hábitos deletérios podem provocar diastemas considerados desfavoráveis ao estabelecimento correto da dentição provocando alterações na harmonia do sorriso.

\section{Resultados e Discussão}

Após o exame dos dados clínicos e radiográficos de 520 jovens entre 07 a 12 anos de idade que freqüentaram a clínica de Odontologia Infantil da Faculdade de Odontologia de Piracicaba, UNICAMP, observou-se 29 jovens com diastemas maiores ou iguais a $1,5 \mathrm{~mm}$.

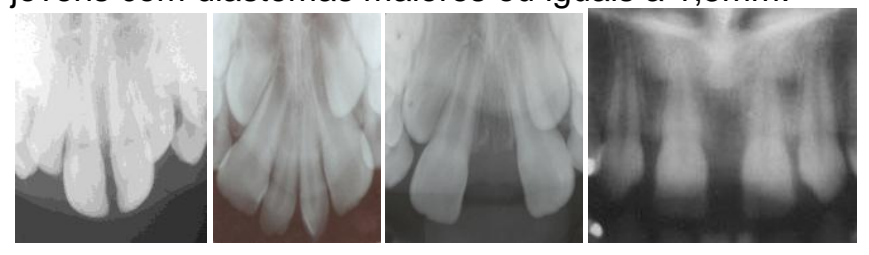

Figura 1. Exemplos de diastemas

Tabela 1: Distribuição de acordo com a faixa etária

\begin{tabular}{|c|c|c|c|c|c|c|}
\hline Idade/Etiologia & 7 & 8 & 9 & 10 & 11 & 12 \\
\hline Espaço ósseo & 6 & 6 & 7 & 2 & 0 & 1 \\
\hline Mesiodens & 1 & 0 & 1 & 0 & 0 & 0 \\
\hline $\begin{array}{c}\text { Agenesia de incisivos } \\
\text { laterais }\end{array}$ & 1 & 0 & 0 & 0 & 1 & 0 \\
\hline Inserção baixa de freio labial & 2 & 1 & 0 & 0 & 0 & 0 \\
\hline Total & 10 & 7 & 8 & 2 & 1 & 1 \\
\hline
\end{tabular}

Tabela 2: Fator etiológico e dimensão do diastema

\begin{tabular}{|c|c|c|c|c|}
\hline Diastema $(\mathrm{mm})$ & $\begin{array}{c}\text { Espaço } \\
\text { ósseo }\end{array}$ & Mesiodens & Agenesia & $\begin{array}{c}\text { Inserção } \\
\text { baixa } \\
\text { freio }\end{array}$ \\
\hline 1,5 a $2,5 \mathrm{~mm}$ & 4 & 0 & 0 & 0 \\
\hline 2,6 a $3,5 \mathrm{~mm}$ & 10 & 0 & 0 & 2 \\
\hline 3,6 a $4,5 \mathrm{~mm}$ & 3 & 1 & 1 & 1 \\
\hline 4,6 a $5,5 \mathrm{~mm}$ & 2 & 1 & 1 & 0 \\
\hline 5,6 a $6,5 \mathrm{~mm}$ & 0 & 0 & 0 & 0 \\
\hline 6,6 a $7,5 \mathrm{~mm}$ & 0 & 0 & 0 & 0 \\
\hline 7,6 a $8,5 \mathrm{~mm}$ & 3 & 0 & 0 & 0 \\
\hline Total & 22 & 2 & 2 & 3 \\
\hline
\end{tabular}

\section{Conclusões}

1- A incidência de diastemas interincisivos centrais superiores permanentes, considerando a totalidade de dos pacientes analisados foi de $5,7 \%$;

2- Com o progredir da idade a incidência de diastemas diminui;

3- O excesso de tecido ósseo foi o fator etiológico mais encontrado;

4- O relacionamento entre a presença do freio labial superior e o diastema foi de $10,33 \%$;

\section{Agradecimentos}

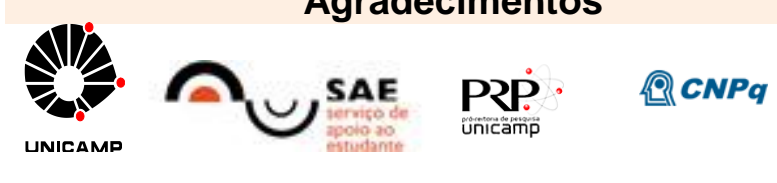

1- Hussaina, U. et al. Etiology and treatment of midline diastema: A review of literature. Pediatr Dent.. 2013,5(1):27-33.

2- Gkantidis, $\mathrm{N}$ et al. Management of maxillary midline diastema with emphasis on etiology. J Clin Pediatr Dent. 2008,32(4): 265-272.

3-Shashua $\mathrm{D}$ et al. reapse after orthodontic correction of maxillary median diastema: a follow-up evaluation of consecutive cases. Angle Orthod 1999, $69(3): 257-263$. 